\title{
Factors in Volunteer Turnover at Nonprofit Organizations: A Study of Lifeline in Taiwan
}

\author{
Tung-Sheng Kuo ${ }^{1}$, Mei-Mei $\operatorname{Lin}^{2} \&$ Chun-Hsiung Lan $^{3}$ \\ ${ }^{1}$ Department of Business Administration, Nanhua University, Chiayi, Taiwan \\ ${ }^{2}$ Department of Business Administration, Tungnan University, Taipei, Taiwan \\ ${ }^{3}$ Department of Business Administration, Hsing Wu College, Taipei, Taiwan \\ Correspondence: Tung-Sheng Kuo, Department of Business Administration, Nanhua University, Chiayi 62249, \\ Taiwan. Tel: 886-5-272-1001\#56546. E-mail: tskuo2@gmail.com
}

Received: October 1, 2012 Accepted: October 22, 2012 Online Published: December 31, 2012

doi:10.5539/ass.v9n1p22 URL: http://dx.doi.org/10.5539/ass.v9n1p22

\begin{abstract}
Volunteers are a group of people willing to provide services and work without pay. The lack of financial incentives and benefits may cause the volunteers to leave at anytime. Most non-profit organizations invest large amounts of time and money to train the volunteers before they come on board; therefore the turnover of volunteers will cause a significant loss for the organization.

This paper is a study on Lifeline in Taiwan; it explores the major reasons for turnover by using a survey on volunteers at 10 Lifeline branches. The results show that although the volunteers have different characteristics, there is no significant difference in the turnover factors or intentions. Through regression, the three factors, leadership style, volunteer assistance programs, incentive programs, have no significant effect on the turnover intention. Finally, this paper makes some practical management suggestions.
\end{abstract}

Keywords: leadership style, volunteer assistance programs, incentive programs, turnover intention

\section{Introduction}

Volunteers are persons who contribute their personal professional knowledge, ability, labor, experience, skill and time to public affairs and social benefits. The main difference between volunteers and employees is salary/payment. Therefore, it is very possible for volunteers to leave as there is no binding contract or financial incentive. In the United States, one out of two people have been volunteers (Silverberg, et al., 2001). In Taiwan, about $15 \%$ of the population has been involved in the volunteer services at some time. The trend shown is one of increasing numbers of volunteers and their increasing importance.

No matter whether it is in the private or public sectors, many organizations rely on the assistance of volunteers, especially the public sector which faces a shortage of human resources and financial resources. Many of the government sectors have started to train volunteers to complete a variety of tasks. Volunteers can not only maintain or even provide more services, but also save resources in the organization. On the other hand, the departure of volunteers will cause losses for the organization. Generally speaking, turnover usually causes a negative impact on the organization, and the cost of employees voluntarily leaving is up to two times their annual salaries (Philips, 1990). Since there is no payment or binding contract for volunteers, the turnover rate is higher. In order not to reduce the impact of volunteers leaving, management should know more about the reasons for their departure.

There are many reasons for leaving a job, such as worker dissatisfaction ( $\mathrm{Lu}$, White and Louise, 2005) and personal reasons (Lee, 2005). Are the reasons for leaving the same for volunteers as they are for general employees? For example, personal reasons: in Lifeline, volunteers mainly play the role of the psychological consular, but still have their own personal issues, such as family, marriage, work and feelings. These are also important factors for consideration by volunteer management.

Among all the factors of turnover discussed in this study, leadership (which has been the common turnover factor in general organizations), volunteer assistance programs and the incentive program require greater consideration. Management of volunteers should be different from general employee management. 
We chose Lifeline Taiwan as the study target, and explored the causes of leaving, as well as the correlations of factors. Lifeline Taiwan is an organization providing 24-hour services, 7 days per week. It needs many volunteers to assist in its operation. However, the training takes a long time, a significant amount of effort and much human capital. The whole training process contains four phases and takes about nine months. Therefore, the turnover creates tangible losses as well as the invisible loss of labor relocation. From the motivation mentioned above, we would like to do more research on volunteers' thoughts and determine the causes of departure, and finally discuss how to handle and prevent it. The aims of this study are: (1) to understand the different personal characteristics and the difference between volunteer's turnover and turnover intention, (2) discuss the correlation between leaving factors and the volunteer's turnover intention, and (3) find out if the leaving factors affect the volunteer's turnover intention.

\section{Literature Review}

\subsection{Leadership}

Leadership is the ability to lead and inspire others to reach a goal (Hemphill \& Coons, 1957); it requires communication and affecting people in certain situations in order to reach a certain goal (Tannenbaum, Weshler \& Massarik, 1961). To leaders, subordinates' trust is deemed to be the factors that affect organizational performance (Burke et al., 2007; Cropanzano \& Mitchell, 2005). The types of leadership differ from leader to leader. Leadership can be classified in the following ways: Trait theory, Situation theory and Behavior theory.

Trait theory emphasizes the special characteristics of the leaders. Ghiselli (1971) summarized a leader as having a supervision capability, wisdom, desire for accomplishment, self-confidence, self-achievement and quick decision-making. Fiedler (1967) proposed the Contingency Model of Leadership. He considered the factors affecting the leadership's efficiency, the relationship of the leader and the followers, working structures and the authority of the position. Situation Theory discussed the relationship between manager and the members. Blake \& Mounton (1978) divided leadership into People-oriented and Production-oriented categories. People-oriented means the leader respects employees and desires to satisfy their needs. Production-oriented leadership focuses on the production efficiency. Based on tasks and relationship behavior, Hersey and Blanchard (1984) categorized the leadership into: Telling type, Selling type, Participating type and Delegating type. Based on their study, this paper categorizes leadership styles into Demanding, Persuading, Participating and Delegating.

\subsection{Volunteer Assistance Program}

The assistance program for volunteers in this paper is similar to the assistance program for employees in a normal organization. The Employee Assistance Program is a service to assist employees who face difficulties or problems with professional assistance in order to improve their productivity at work (Employee Assistance Professionals Association, 2010). Over years its role is not only to improve productivity, but also to solve work-related problems (Anema \& Sligar, 2010). Thus, the Employee Assistance Program can be treated as a people-oriented benefit management. Usually, professional consultants will provide proper assistance and employees may resolve their problems with personal, family or work-related issues. If an organization fully utilizes the employee assistance program, it may not only reduce the pressure on employees and increase their productivity, but also lower the cost of annual medical insurance and special healthcare (Smith, 1994). In this paper, the employee assistance program covers an even broader area; in addition to the service of resolving employee's problems, it includes the service of improving employee's work performance. According to Lifeline, the volunteer's assistance program includes the consulting program, family assistance program and volunteer benefit program.

\subsection{Incentive Program}

The Incentive Program is a kind of management with a proper structure and design to induce employees to reach the organization's goals. In the early stages, researchers put more emphasis on monetary rewards; they consider money as the only motivation to work. In recent research, the incentive program was considered in a broader perspective. For example, some researchers classified the incentive programs as a financial incentive program and a non-financial program. The financial incentive program includes a salary system and incentive monetary rewards; the non-financial incentive program includes a personal life development plan, prize rewards and travel rewards (Abrantt and Smythe, 1989). Greenburg and Liebman (1990) categorized the incentive programs into three types: material reward, social reward and activity reward. Material rewards include all the financial rewards to satisfy employees, such as monetary rewards, commissions, prizes, and travel plans. Social rewards aim to satisfy the need for relationships and being respected, such as recognition of contribution/ performance, or promotion. Activity rewards aim to satisfy the need for self-achievement and self-growth, such as attained through competition and the in-job training program. This study uses these three types as the incentive programs. 


\subsection{Turnover Intention}

Turnover occurs when members of the organization voluntarily resign from their jobs and leave the organization (Allen, Weeks \& Moffitt, 2005; Mobley, 1977). Turnover intention is the thought the employee has before officially resigning; this may include the willingness, capability and planning of the resignation. Although the turnover intention is not actual behavior (Price \& Mueller, 1986), through the research on turnover intention, management may also understand or predict the real behavior of resignation in order to comfort that leaving employee, or for HR reassignment. Turnover can be voluntary or involuntary (Ferguson, 1986). Voluntary leave is leave by personal decision and involuntary leave is due to uncontrollable reasons, such as retirement or death. In this paper, turnover intention means voluntary leave.

\subsection{Related Studies}

There are many factors affecting turnover intention, such as personal factors, the job itself, the organization and the environment. Personal factors, such as willingness to work and career development, have positive correlations with turnover intention. According to Bedeian \& Armenakins (1981), there is a positive relation between tension/pressure caused by work and turnover intention. Igbaria \& Siegel (1992) pointed out that educational level, working experience and age were significant factors. Price \& Muller (1986) found the salary and responsibility to family were significant variables.

Seybolt's study (1983) of nurses and job factors, found that turnover intention is predictable by job function. According to Hackman \& Maccoby (1971), the less repetitive the nature of the job, the lower the turnover intention; and the higher the self-determination, the lower the turnover intention. Byars and Rue's study (1994) found that job rotation and turnover intention was negatively correlated, that is, the more the job rotation, the lower the intention to leave. In addition, leadership style was found to have indirect effect on turnover intention (Tremblay, 2010). In regard to organization and environment, support from the organization or manager will reduce the intention to leave (Kottke \& Sharkfinski, 1988). The organization policy also affects the turnover intention (Seybolt, 1983).

All the above researches focus on general institutions. Any discussion about volunteers was limited to the public sector only. This paper focuses on the turnover intention of volunteers in nonprofit organizations, with a discussion on organization factors at the end. We used "Volunteer Assistant Program" and "Incentive Program" as variables and tried to understand more about volunteers, in order to obtain a better volunteer management system.

\section{Research Design}

\subsection{Assumptions and Design of the Questionnaire}

Based on the discussion of the literature, the assumptions were proposed as follows:

1) The impacts of leadership, the volunteer assistant program, the incentive program and organization related to turnover intention were not significantly different for different characteristics

2) Correlations exist among leadership, the volunteer assistant program, the incentive program and turnover intention.

3) Leadership, the volunteer assistant program and the incentive program will affect turnover intention.

The development of the questionnaire referred to past studies, considered the characteristics of volunteers and consulted with professionals. Using a five point Likert Scale, the structured questionnaire includes five sections: Leadership, Volunteer Assistant Program, Incentive Program, Turnover Intention and Personal Characteristics. Types of leadership were: Telling Type, Selling Type, Participating Type and Delegating Type. There were 15 questions in total. The Volunteer Assistance Program included the consulting program, the family assistance program and the volunteer benefit program, with 15 questions in total. The Incentive Program was considered to comprise Material Rewards, Social Rewards and Activities Rewards, with 14 questions in total. There were 5 questions for Turnover intention. Personal characteristics included gender, age, years of services (seniority), marriage status and highest education diploma.

The population studied included all the volunteers of Lifeline. We first focused on two units for projection, collected the questionnaires from the two units, modified the questions and then used the modified questionnaire for the other 10 units. Of a total of 460 questionnaires that had been sent out, 235 questionnaires were considered valid samples. The basic information of the samples is shown in Table 1. 
Table 1. Sample information

\begin{tabular}{llll}
\hline Variable & Groups & Volunteers & Percentage \\
\hline Gender & Female & 168 & 71.5 \\
Age & Male & 67 & 28.5 \\
& $24-30$ & 22 & 9.4 \\
& $31-40$ & 30 & 12.8 \\
& $41-50$ & 125 & 53.2 \\
Seniority & $51-60$ & 25 & 10.6 \\
& 60 and above & 33 & 14 \\
& $0-5$ & 83 & 35.3 \\
& $5-10$ & 71 & 30.2 \\
& $11-15$ & 45 & 19.1 \\
& $16-20$ & 18 & 7.7 \\
Marriage Status & $20-25$ & 14 & $6 \%$ \\
& 26 and above & 4 & 7 \\
Highest Diploma & Married & 167 & 71 \\
& Single & 53 & 22.3 \\
& Others & 15 & 6.4 \\
& High School & 76 & 32.3 \\
College & 68 & 29 \\
& University & 84 & 35.7 \\
& Master and above & 7 & 3 \\
\hline 3.2 Data Analsis and & & & \\
& & &
\end{tabular}

\subsection{Data Analysis and Regression}

After collecting the test questionnaires, we analyzed the factors in order to have a better construct viability. By calculating each sector, the KMO was 0.919 for Leadership, 0.923 for Volunteer Assistance Program, 0.938 for Incentive Program and 0.6553 for Turnover Intention. The results showed high positive correlations between the variables. For the confidence interval, the Cronbach's $\alpha$ value was 0.8928 for Leadership, 0.9218 for Volunteer Assistance Program, 0.8891 for Incentive Program and 0.6553 for Turnover Intention. This showed that the confidence interval was in the acceptable range.

Next, SPSS was used for data analysis. Whereas the descriptive statistics was used for volunteers' personal characteristics and variable distribution, t-test, one-way Analysis of Variance (ANOVA), Pearson Product Moment Correlation Coefficient and regression analysis were used to analyze the all hypotheses. The descriptive Statistics focuses on personal data and a single question, frequency of sample distribution, effective rate, maximum, minimum, mean and standard deviation, in order to understand the basic features. The t-test and ANOVA was used to test personal variables (gender, age, seniority, marriage status and highest diploma) for the difference for turnover reasons. The correlation analysis was used to tests the degree of the relationships between turnover factors and turnover intention. The regression analysis was used to test if the turnover factors can predict the turnover intention.

\subsection{Research Findings}

In the area of Descriptive Statistics, each unit's manager leadership-average was 3.5217 for participating type (highest) and 2.9116 for telling type (second). It showed that most of the volunteers wanted to be respected and cared for by their managers, not just to be acknowledged for their task achievement. In the Volunteer Assistant Program, the highest average of 3.9904 was for the volunteer benefit program, and next highest average was 3.6614 for the consulting program. It showed that Lifeline preferred Family Assistant Program less. In regard to the Incentive Program, the average was 2.4235 for volunteer's appreciation of the overall incentive program; although it was less than the mean of 3, the material rewards average was 3.1787 , social rewards average was 3.3366. It showed that the volunteers had lower recognition on the incentive program, but agreed with monetary 
rewards. In regard to Turnover Intention, volunteers' average value was 1.7597 , lower than the mean of 3 . It showed that volunteers did not have a strong intention to leave.

In the study, t-test and ANOVA were used to analyze the differences among variables for turnover reasons. Using $\mathrm{t}$-test, there was no significant difference between female and male for all turnover factors (either considering or having intention), except for Consulting Assistance Program. There was a significant difference in leadership among different service types of volunteers. In regard to the Incentive Program, there was no significant difference except for material incentive program. Using ANOVA, we analyzed the differences (in thinking about leave or having the intention due to the leaving factors) among age, seniority, marriage status and highest diploma. The results are listed below.

There was no significant difference between the ages for the factors of leaving, except for leadership. There was no significant difference among the education level and the factors for leaving. For the correlation of variables, leadership versus the volunteer assistance program and the incentive program, the correlation coefficients were 0.623 and 0.605 , respectively. Both of them reached a significant level. This showed the positive correlation between leadership and the two variables, but leadership showed a low negative correlation $(-0.190)$. The correlation of volunteer assistance program and inventive program also reached a significant level $(\mathrm{r}=0.641$ and $\mathrm{p}=0.000)$, but turnover intention showed a negative correlation $(-0.203)$. Besides, the Incentive Program and turnover intention showed low negative correlation $(-0.310)$. Overall, leadership, volunteer assistance program and inventive showed low negative correlations to the turnover intention. The results are summarized in Table 2 .

Table 2. Variables correlations

\begin{tabular}{|c|c|c|c|c|c|}
\hline & & Leadership & Assistance program & Incentive program & Turnover intention \\
\hline \multirow[t]{2}{*}{ Leadership } & Pearson correlation & 1 & & & \\
\hline & Significance & & & & \\
\hline \multirow[t]{2}{*}{ Assistance program } & Pearson correlation & $0.623 * *$ & 1 & & \\
\hline & Significance & 0.000 & & & \\
\hline \multirow[t]{2}{*}{ Incentive program } & Pearson correlation & $0.605 * *$ & $0.641 * *$ & 1 & \\
\hline & Significance & 0.000 & 0.000 & & \\
\hline \multirow[t]{2}{*}{ Turnover intention } & Pearson correlation & $-0.190 * *$ & $-0.203 * *$ & $-0.310 * *$ & 1 \\
\hline & Significance & 0.003 & 0.002 & 0.000 & \\
\hline
\end{tabular}

Finally, through regression, among the leaving factors, leadership has a significant effect on turnover intention $(\mathrm{F}=8.762, \mathrm{P}=0.000)$, which may explain the variance of $19.0 \%$. That is, the closer leadership is to the participating type, the lower the turnover intention. The Volunteer Assistance Program is also significant ( $\mathrm{F}=9.983, \mathrm{P}=0.002$ ). This may explain the variance of $20.3 \%$, i.e., the more care for the employees' assistance program, the lower the turnover intention. The Incentive Program was also significant $(F=0.487, p=0.012)$, and this may explain the variance of $16.5 \%$, i.e., a proper incentive program will satisfy the employees, so it will lower the intention to leave. All the results are summarized in Table 3.

Table 3. Results of regression analysis

\begin{tabular}{ll}
\hline Predicted variables & \multicolumn{1}{c}{ Turnover Intention } \\
\hline Leadership & \\
b & 0.190 \\
F-Value & $8.762^{* * *}$ \\
P-value & 0.000 \\
Volunteer Assistant Program & \\
b & 203 \\
F-Value & $9.983^{* *}$ \\
P-value & 0.002 \\
Incentive Program & \\
b & 0.165 \\
F-Value & $0.487^{*}$ \\
P-value & 0.012 \\
\hline
\end{tabular}




\section{Conclusion and Suggestions}

Through this research, we found that most of the volunteers expected the manager to practice participating leadership. The institute should also focus on the volunteer benefit program rather than family assistance program. Overall, volunteers agreed with the incentive program, and had no strong intention to leave. Concerning the variance analysis, there was no significant difference in the leaving factors between females and males. Besides, there was no significant difference between leaving factors among the different personal characteristics. On the correlation analysis, there were significant correlations among leadership, Volunteer Assistance program and the Incentive Program, but the three showed a low negative correlation. Last, the regression analysis, leadership, Volunteer Assistant Program and Incentive Program showed a significant effect, which means that volunteer turnover was not affected by these factors. It could be possible that volunteers are willing to devote themselves without considering the return. Even so, Management may try to improve the working environment in order to have volunteers feel that they belong to the organization.

Most of organizations lack a Family Assistance Program. However, Lifeline provides 24 hours service, 7 days a week. Most of the volunteers at Lifeline were married females, who gave up family time for this volunteer service. Providing a family assistance program would be a considerate policy. In addition, participating leadership is the type most expected by the employees. Most of the volunteers at Lifeline provided their services without pay, and were willing to provide the services anytime needed. The management team of Lifeline and other nonprofit organizations should think about their leadership style, in order to have the volunteers feel more productive and that they belong to the organization.

\section{References}

Abrant, R., \& Smythe, M. R. (1989). A survey of sales incentive programs. Industrial Marketing Management, 18, 209-214. http://dx.doi.org/10.1016/0019-8501(89)90037-0

Allen, D. G., Weeks, K. P., \& Moffitt, K. R. (2005). Turnover intentions and voluntary turnover: the moderating roles of self-monitoring, locus of control, proactive personality, and risk aversion. Journal of Applied Psychology, 90, 980-990. http://dx.doi.org/10.1037/0021-9010.90.5.980

Anema, J. C. Jr., \& Sligar, S. R. (2010). Innovation in the workplace: evaluation of a pilot employee assistance program serving persons with disabilities. Journal of Rehabilitation, 76(4), 9-17.

Bedeian, A. G., \& Armenakis, A. A. (1981). A path-analytic study of consequences of role conflict and ambiguity. Academy of management Journal, 24, 471-424. http://dx.doi.org/10.2307/255852

Blake, R. R., \& Mouton, J. S. (1978). The New Managerial Gird. Houston: Gulf Publishing.

Burke, C. S., Sims, D. E., Lazzara, E. H., \& Salas, E. (2007). Trust in leadership: a multi-level review and integration. The Leadership Quarterly, 18, 606-632. http://dx.doi.org/10.1016/j.leaqua.2007.09.006

Byars, L. L., \& Rue, L. W. (1994). Human Resource Management. Burr Ridge: Irwin.

Cropanzano, R., \& Mitchell, M. S. (2005). Social exchange theory: an interdisciplinary review. Journal of Management, 31, 874-900. http://dx.doi.org/10.1177/0149206305279602

EAPA Press. (1996). Guideline for international EAPs. EAPA Exchange, 2, 24-27.

Employee Assistance Professionals Association. (2010). EAPA standards and professional guidelines for employee assistance programs. Retrieved from http://www.valueoptions.com/providers/Handbook/treatment/EAP_Guidelines.pdf

Ferguson, G. H. (1986). Distinguishing voluntary from involuntary nurse turnover. Nursing Management, 17(12), 43-44. http://dx.doi.org/10.1097/00006247-198612000-00018

Fiedler, F. E. (1967). A theory of leadership effectiveness. New York: McGraw-Hill.

Ghiselli, E. (1971). Exploration in managerial talent. New York: McGraw-Hill.

Greenberg, J., \& Liebman, M. (1990, Ju1/Aug), Incentives: the missing in strategic performance. The Journal of Business Strategy, 8-11. http://dx.doi.org/10.1108/eb060067

Hackman, J. R., \& Maccoby, E. E. (1971). Employee reactions to job characteristics. Journal of Applied Psychology, 55, 256-286. http://dx.doi.org/10.1037/h0031152

Hemphill, J. K., \& Coons, A. E. (1957). Development of the leader behavior description questionnaire. In R. M. Stogdill (Ed.), leader behavior: its description and measurement. Columbus: Ohio State University, Bureau of Business Research. 
Hersey, P., \& Blanchard, K. (1984). Managing Organizational Behavior. Englewood Cliffs, N.J.: Prentice-Hall.

Igbaria, M., \& Siegel, S. R. (1992). The reason for turnover of information system's personnel. Information and Management, 23, 321-330. http://dx.doi.org/10.1016/0378-7206(92)90014-7

Kottke, J. L., \& Sharafinski, C. E. (1988). Measuring perceived supervisory and organizational support. Educational and Psychological Measurement, 48, 1075-1079. http://dx.doi.org/10.1177/0013164488484024

Lee, K. A. (2005). The effects of locus of control and organizational structure on job satisfaction and turnover intention of hotel managerial employees (Unpublished doctoral dissertation). Oklahoma State University. Stillwater, Oklahoma.

Mobley, W. H. (1977). Intermediate linkages in the relationship between job satisfaction and employee turnover. Journal of Applied Psychology, 62, 237-240. http://dx.doi.org/10.1037/0021-9010.62.2.237

Phillips, J. D. (1990). The price tag on turnover. Personnel Journal, 12, 58-61.

Price, J. L., \& Mueller, C. W. (1986). Absenteeism and turnover of hospital employees. Greenwich, CT: JAI Press.

Seybolt, J. W. (1983). Dealing with premature employee turnover. California Management Review, 25, 7-117. http://dx.doi.org/10.2307/41165019

Silverberg, K., Marshall, E., \& Ellis, G. (2001). Measuring job satisfaction of volunteers in public parks and recreation. Journal of Park and Recreation Administration, 19, 79-92.

Smith, S. L. (1994). Owens-corning: insulating against high disability costs. Occupational Hazards, 56(7), 33-38.

Tannenbaum, R., Weshler, I. R., \& Massarik, F. (1961). Leadership and Organization. New York: McGraw-Hill.

Tremblay, M. A. (2010). Fairness perceptions and trust as mediators on the relationship between leadership style, unit commitment, and turnover intentions of Canadian forces personnel. Military Psychology, 22, 510-523. http://dx.doi.org/10.1080/08995605.2010.513271 